\title{
Document Delivery: A Comparison of Commercial Document Suppliers and Interlibrary Loan Services
}

\section{Kathleen Kurosman and Barbara Ammerman Durniak}

\begin{abstract}
Cost-effective and timely document delivery is becoming a major concern as many academic libraries face cuts in serials budgets. This study examines the costs and response times of traditional interlibrary loan (ILL) services and four commercial document suppliers. From October 1991 to February 1992, a total of 52 periodical requests were sent through Online Computer Library Center's (OCLC's) Interlibrary Loan subsystem simultaneously to academic libraries and to four document suppliers. Data were gathered on each supplier's ability to fill the requests, and the costs, turnaround times, and the quality of the articles supplied. Results indicated that traditional ILL was the most cost-effective and one of the quickest means of obtaining articles not owned by our library.
\end{abstract}

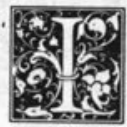

n 1990 Vassar College, like many other colleges and universities, was forced to cut its serials budget. An intense review by librarians, faculty, and the administration resulted in a 25 percent reduction of serial subscriptions. By May of 1991, 1,100 titles had been selected for cancellation. Although some of the titles cancelled were of marginal utility, a number of useful journals were sacrificed. One outgrowth of this experience was an interest in exploring alternative means of obtaining journal articles.

Vassar College, established in 1861 as the first college to offer a liberal arts education to women, became coeducational in 1967, and has a current enrollment of 2,272 students and a faculty of more than 200. Despite the cancellation project, Vassar's serial holdings are extensive, comprising over 3,000 nonGPO titles. However, the research needs of faculty and students are such thatconventionalinterlibraryloan(ILL) has been an integral part of the research process for many years. In 1991/92, faculty borrowed 1,194 journal articles and 1,371 articles were borrowed by students. Charges for materials ordered by faculty are absorbed by the library, while students must pay any fees incurred.

Although patrons were generally satisfied with the turnaround time for filling requests via ILL, there was some concern that ILL would not be able to provide quick enough delivery of articles from some of the journals cancelled during the serials review. While we were aware of the existence of other document-delivery options, we had not ever used any of these services. We were interested in finding out how some of these alternatives compared to ILL in ability to supply requested items, cost, delivery

Kathleen Kurosman is Coordinator of External Resources and Barbara Ammerman Durniak is Electronic Reference Services Librarian at Vassar College Libraries, Poughkeepsie, New York 12601. 
time, and quality of copies. A grant from Vassar's Research Committee enabled us to conduct a limited study which examined these factors.

\section{LITERATURE REVIEW}

A search of the literature revealed that some investigation into this area had already been done. In 1985 a study conducted by Jean Currie at the Albert R. Mann Library of Cornell University compared the costs and turnaround times of three different types of document delivery services: "publicationspecific" (ISI's Genuine Article, CAS, and $\mathrm{CAB}$ ), commercial (Information on Demand), and library-based (RLIN or ALA forms). ${ }^{1}$ Dialog's DialOrder was used to place orders with the publication-specific services and with Information on Demand. Currie concluded that there was little difference among the three sources in terms of turnaround time, but there was a significant difference in terms of cost, with ILL clearly the most cost-effective. Hurd and Molyneux compared conventional ILL service to the UMI Article Clearinghouse in order to fill article requests for the University of Virginia's Science and Engineering Library. ${ }^{2}$ All requests were sent via OCLC's ILL subsystem. They found that UMI delivered documents more quickly than ILL, at a slightly higher price. A third study, conducted at the University of Illinois at Chicago by Miller and Tegler, reordered previously requested articles from various commercial suppliers available through Dialog's DialOrder service. $^{3}$ The authors found that commercial suppliers charged more but did not necessarily provide faster service than ILL.

Despite the fact that some comparisons between ILL and commercial document delivery services had already been drawn, we decided to continue with our study for several reasons. First, the Currie, Hurd, and Miller studies all were conducted at scientific, primarily graduate-level libraries, and we were uncertain that the conclusions drawn from them would apply to an undergraduate liberal arts college. Second, only one of the studies used the ILL subsystem to transmit ILL requests, and we were interested in seeing whether cost analyses would be the same for requests transmitted via OCLC as they were for the studies which used Dialog for verification and ordering. Finally, we planned to investigate the performance of five document suppliers systematically, something none of the other studies had done.

\section{THE COMMERCIAL SUPPLIERS}

The document suppliers chosen represent two distinct service approaches. The UMI Article Clearinghouse (UMI) and ISI's The Genuine Article (TGA) are based on fixed inventories of journals. The UMI Article Clearinghouse, introduced by University Microfilms in 1983, has holdings of 12,500 journals, magazines, conference proceedings, newspapers, and government documents in a closed, in-house collection. Coverage ranges from general-interest periodicals to highly specialized publications, with an emphasis on scientific and technical literature. Other concentrations include business, science, arts and humanities, international affairs, and social sciences. The clearinghouse provides forty-eighthour in-house turnaround for articles published within the last five years. ${ }^{4} \mathrm{Ar}-$ ticles can be ordered through OCLC, BRS, Dialog DialOrder, telephone, etc., and will be available through CitaDel and OCLC's FirstSearch. Articles can be delivered by mail or fax and will also be provided via Ariel. UMI is at present working with Wilson on an agreement to supply full text for citations found in the Wilson databases.

The Genuine Article (TGA) is the document delivery service of the Institute for Scientific Information (ISI), Philadelphia. Over 6,000 titles, covering the social sciences, sciences, arts, and humanities, are listed in The Genuine Article Source Publication Listing, which includes both the standard service (current year and past four calendar years) and an extended service which covers about 3,500 journals with some issues dating back to the 1800 s. The Genuine Article is 
also the source for copies of articles cited in ISI publications such as Current Contents, Social Science Citation Index, and Science Citation Index.

Articles from the standard service will be provided either in the form of "tear sheets," articles torn from the original journal, or photocopies if no tear sheets are available. Only photocopies are provided for articles ordered through the extended service. Articles can be ordered by mail, telephone, fax, e-mail, or online through OCLC, BRS, Dialog, etc.

Two other document delivery services have "open inventories" in the sense that they have staff in or have agreements with university libraries and research centers to provide articles. Information on Demand (IOD), a subsidiary of Maxwell Online at the time of the study, is based in Virginia and was founded in 1972. IOD provides items such as journal articles, technical reports, conference papers, government documents, patent information, standards and specifications, etc., from staffed sources at institutions such as the University of California, University of Michigan, University of Texas, University of Virginia, Library of Congress, and Stanford University. In addition to staffed sources, IOD has a number of in-house collections: Biomedical SpecialList Collection, NTIS Report Collection, GAO Legislative History Service, and Japan Technology Database Documents. Items not available from a staffed source or IOD collection may be available through an international network which includes sources such as the National Library of Medicine, the British Library Document Supply Centre, Centre National de la Recherche Scientifique (France), and the Lenin State Library. If necessary, staffers go to publishers, private information centers, and even authors. IOD also has a customized information retrieval service called Research on Demand. Orders can be placed through OCLC, BRS, Dialog, IOD Direct, mail, phone, or fax.

The Information Store (TIF) is based in San Francisco and advertises itself as able to provide "anything ever published, anywhere in the world." ${ }^{5}$ TIF will supply journal articles, proceedings, government reports, theses, translations, newsletters, price lists, etc. TIF does not maintain an inventory and relies heavily on the University of California system for its document retrieval. Orders can be placed through OCLC, BRS, DialOrder, and a number of other online methods as well as by fax.

\section{METHODOLOGY}

Of the many document delivery options, we decided to investigate only commercial document delivery services which allowed ordering through the OCLC subsystem. The decision was made for the following reasons: (1) the fact that orders could be placed via OCLC obviated the need for specialized training of the ILL office staff (in the use of Dialog's DialOrder, for instance) and also meant that no reorganization of the workflow was necessary; and (2) no specialized equipment was needed. Beginning the first week of October 1991, one ILL periodical request was chosen randomly each day (Monday-Thursday), and requests were sent simultaneously through the OCLC-ILL subsystem to ILL-participating libraries and to each of the four suppliers. Except when no "source of information" was given, no further verification was done. For the two suppliers with fixed inventories, requests were only sent if the needed journal appeared on the inventory list. It was assumed that ILL, IOD, and TIF could fill any request received; accordingly, all requests were directed to these sources. Although several of the suppliers offered quicker means of sending materials, such as fax or overnight delivery, in order to contain costs, all articles were sent via U.S. mail. Records were kept for each request sent out. The first copy received was sent to the patron; subsequent copies were kept. The study ran from October through the end of February 1992, at which point funding ran out. No tests were run for a six-week period beginning mid-December, since the college was on break and few requests were generated. In all, the study comprised 14 weeks, with 52 requests being sent. Data collection ended 
on May 19, 1992, with receipt of the last outstanding request.

\section{DESCRIPTION OF REQUESTS}

The 52 randomly selected requests amounted to approximately 5 percent of all articles requested (1099) during the 6-week time period. Each of the 52 titles requested was unique; there were no repeats. Student requests totaled 79 percent; the remaining 21 percent were ordered by faculty. Publication dates ranged from 1918 to 1991 , the majority within the last five years. Page lengths ran from 1 to 41 . All but 9 articles were English-language. With respect to subject matter, a breakdown by LC classification revealed that the majority of requests were for articles from journals in the social sciences (22), followed by the sciences (14), language and literature (9), and general (7). A "source of information" was supplied for all but 5 requests. CD-ROM indexes were cited most often (25), followed by bibliographies (16), paper indexes (5), and an online database (1).

\section{FILLING OF REQUESTS}

We first examined the success of each document supplier in providing the articles needed by our patrons. Because two of the suppliers (TGA and UMI) had fixed inventories, we knew in advance whether or not an article from a particular journal could be supplied. Of the 52 requests, 22 titles were available from UMI and 12 were available from TGA. For the other 3 suppliers (IOD, ILL, and TIF), it was assumed that, potentially, they could supply any article requested; accordingly, all 52 requests were sent to these 3 suppliers.

Every article requested was delivered by at least 1 of the 5 document suppliers, but only 4 requests ( 7.7 percent) were filled by all 5 . Of the 52 articles requested, 2 were filled by only 1 supplier, the remaining articles were filled by 2 or more suppliers. Table 1 compares the potential and actual performance of the five suppliers.

Since all but 2 requests were filled by more than 1 supplier, we were curious
TABLE 1

POTENTIAL VERSUS

ACTUAL PERFORMANCE BY DOCUMENT SUPPLIER

\begin{tabular}{lccc}
\hline Supplier & $\begin{array}{c}\% \\
\text { Potential } \\
\text { Performance }\end{array}$ & $\begin{array}{c}\% \\
\text { Actual } \\
\text { Performance }\end{array}$ & $\begin{array}{c}\text { No. } \\
\text { Filled }\end{array}$ \\
\hline TIF & 100 & 89 & 46 \\
IOD & 100 & 87 & 45 \\
ILL & 100 & 83 & 43 \\
UMI & 40 & 100 & 22 \\
TGA & 23 & 83 & 10 \\
\hline
\end{tabular}

about why some suppliers were able to furnish the article when others could not. An unfilled request was defined as one which the supplier potentially could supply but did not. Also included in this definition were requests reported as filled and sent by the supplier but never received. Of the 2 fixed-inventory suppliers, UMI filled all requests and TGA filled all but 2 . One article was unfilled because TGA was under contract with the publisher to supply only original copies of that article, and their supply of originals was exhausted; no explanation was given for the other unfilled request.

The problem of items being sent but not received was also encountered with IOD and TIF, but seemed most serious with IOD. Of the 8 articles not supplied by IOD, 5 were sent, according to IOD, but never received. Four of the articles were listed on the same (November) invoice, so it is likely that they were shipped together and the parcel lost ( 3 of the 4 articles were requested within a week of each other; the remaining article was requested 3 weeks earlier). The last unreceived article was requested in February. We were charged for these 5 items. Of the remaining 3 unfilled requests, 2 were reported as being "unobtainable."

After exhausting "all" other sources, IOD offered to contact the author for 1 article, but the article was never received. We were charged the $\$ 4$ fee for unfilled requests and an additional $\$ 2$ for reference work (see the COST section for an explanation of pricing structures). In the meantime, this item had been supplied 
via ILL from Hunter College in 10 days. We were not charged for the remaining unfilled requests, but we were told the title was unavailable from the 2 libraries identified by IOD as holding that title. This article was also received through ILL, from the University of Texas at Austin, with a turnaround time of 15 days.

TIF was unable to supply 6 articles. One request was filled incorrectly, and 5 were unfilled. No explanations were given as to why 2 of these articles could not be located. The 3 other requests, unfilled because TIF could not locate them in any libraries, were all Spanish-language items. Two of these items were supplied by ILL (from the University of Texas at Austin and from Syracuse University), and 1 was supplied by IOD.

\section{DELIVERY TIME}

Another important criterion was the speed with which requests were filled. Delivery time was defined as the number of calendar days between the sending of a request and receipt of the document. Of the 52 articles requested, 3 (6 percent) were either received from only 1 supplier or else arrived the same day from multiple suppliers. Overall, ILL delivered documents on the most timely basis; 65 percent of the time, ILL was the first to send the article. Additionally, articles requested via ILL were least likely to be received last ( 9 percent). The supplier with the slowest turnaround time was IOD; this supplier was able to fill requests first only 16 percent of the time, and was the last to supply 60 percent of the time. Table 2 shows the average turnaround time in days for the 5 suppliers and also compares them in terms of overall timeliness.

For several titles, one supplier was able to send the article quite quickly, while other suppliers took considerably longer. For 14 articles, the number of days between receipt from the first supplier and the last was under 10 days. For 19 titles, the differential ranged from 11 to 20 days; in 8 cases, there was a differential of 21 to 30 days; for three articles, the differential ranged from 31 to 40 days; and for 5 articles, the differential
TABLE 2

DELIVERY TIME BY

DOCUMENT SUPPLIER

\begin{tabular}{lcrrrr}
\hline Supplier & $\begin{array}{c}\text { Average } \\
\text { Time }\end{array}$ & \multicolumn{2}{c}{ Fastest } & \multicolumn{2}{c}{ Slowest } \\
\hline TGA & 12 & $40 \%$ & $(4)$ & $20 \%$ & $(2)$ \\
ILL & 13 & $65 \%$ & $(28)$ & $9 \%$ & $(4)$ \\
UMI & 15 & $49 \%$ & $(11)$ & $14 \%$ & $(3)$ \\
TIF & 22 & $21 \%$ & $(10)$ & $37 \%$ & $(16)$ \\
IOD & 23 & $16 \%$ & $(7)$ & $60 \%$ & $(27)$ \\
\hline
\end{tabular}

was between 41 and 90 days. Of special interest were the articles with receipt differentials of over 30 days. Table 3 compares the number of days it took for each supplier to fill these 9 requests. Additionally, the charges of each supplier are also given.

\section{COST}

In 1972 the Palmour study reported that the average cost of borrowing an item via ILL was $\$ 7.61 .^{6}$ In 1990 the University of Pennsylvania, using a methodology developed by Dickson and Boucher, calculated the per-title borrowing cost for that institution to be $\$ 17.83 .{ }^{78}$ A study done at the University of Wisconsin system in 1991 found that the average cost of borrowing a journal article was $\$ 6.26 .^{9}$ A recent study of ILL costs for ARL libraries put the average cost of borrowing an item at $\$ 18.62 .^{10}$

\section{Since all but two requests were filled by more than one supplier, we were curious about why some suppliers were able to furnish the article when others could not.}

These figures were derived by factoring in direct costs as well as indirect costs, such as staff time and supplies associated with the filling of requests. Additionally, since libraries which borrow materials also have an obligation to lend, the cost of lending an item may also be considered part of the cost of each ILL transaction. The University of Wisconsin study found the total cost of 
TABLE 3

COMPARISON OF DELIVERY TIMES

\begin{tabular}{|c|c|c|c|}
\hline Journal Title & Supplier & $\begin{array}{c}\text { Delivery Time } \\
\text { (Days) }\end{array}$ & Charges \\
\hline \multirow[t]{3}{*}{ Psych. Aspects of Mental Retardation } & TIF & 96 & $\$ 27.75$ \\
\hline & IOD & 25 & 33.00 \\
\hline & ILL & 6 & 4.40 \\
\hline \multirow[t]{3}{*}{ Le Figaro Litteraire } & TIF & 104 & $\$ 27.75$ \\
\hline & IOD & 15 & 14.92 \\
\hline & ILL & Unfilled & \\
\hline \multirow[t]{3}{*}{ Journal of the Ancient Chronology Forum } & IOD & 85 & $\$ 49.00$ \\
\hline & TIF & filled incorrectly & 27.75 \\
\hline & ILL & 14 & 0.00 \\
\hline \multirow[t]{5}{*}{ World Health Organization Bulletin } & UMI & 77 & $\$ 9.75$ \\
\hline & ILL & 18 & 0.00 \\
\hline & TIF & 11 & 15.25 \\
\hline & TGA & 11 & 9.95 \\
\hline & IOD & unfilled & \\
\hline \multirow[t]{4}{*}{ Journal of Clinical Psychiatry } & UMI & 54 & $\$ 9.75$ \\
\hline & IOD & 22 & 25.00 \\
\hline & TIF & 9 & 15.25 \\
\hline & ILL & 5 & 0.00 \\
\hline \multirow[t]{4}{*}{ Entomologica Scandinavia } & ILL & 47 & $\$ 5.60$ \\
\hline & IOD & 29 & 24.24 \\
\hline & TIF & 9 & 19.75 \\
\hline & TGA & 8 & 14.95 \\
\hline \multirow[t]{4}{*}{ Mosaic } & ILL & 45 & $\$ 0.00$ \\
\hline & TIF & 17 & 18.50 \\
\hline & IOD & 17 & 22.26 \\
\hline & UMI & 9 & 9.75 \\
\hline \multirow[t]{5}{*}{ Environmental Entomology } & IOD & 45 & $\$ 17.17$ \\
\hline & TIF & 10 & 17.25 \\
\hline & UMI & 8 & 9.75 \\
\hline & TGA & 8 & 9.95 \\
\hline & ILL & 7 & 0.00 \\
\hline \multirow[t]{5}{*}{ Michigan Quarterly Review } & TIF & 42 & $\$ 27.75$ \\
\hline & IOD & 11 & 19.58 \\
\hline & UMI & 9 & 9.75 \\
\hline & TGA & 8 & 14.95 \\
\hline & ILL & 8 & 0.00 \\
\hline
\end{tabular}

an ILL article exchange to be $\$ 11.49$ (\$6.26 for borrowing, \$5.23); using figures from the ARL study, (\$18.62 for borrowing, $\$ 10.93$ for lending), the average cost per filled transaction reaches $\$ 29.55$.

In our study all costs refer to direct charges, that is, fees levied by suppliers, both commercial and traditional ILL. Indirect costs were not addressed because the amount of staff time spent choosing an appropriate supplier, inputting requests, troubleshooting "problem" citations, monitoring receipt of articles, sending out requests to patrons, record keeping, paying invoices, and compiling statistics was constant across suppliers.

Fee structures were provided by each commercial document delivery supplier 
(Note: costs cited are those in effect at the time of the study). Some of the commercial suppliers allow patrons to set up deposit accounts which are slightly less expensive than open accounts. Other suppliers base their rates on the volume of items requested. Another option is paying on a per-item basis.

UMI has two levels of deposit account: individual institution ( $\$ 9.75 /$ item) and multi-institutional (pricing for this account varies based on volume). Open invoice charges are $\$ 11.75 /$ item. Except for special-delivery charges, no additional costs are applicable. TGA's prices changed as of January 1992; articles invoiced before that date cost $\$ 9.50$ per item for libraries with a deposit account, $\$ 9.95$ for an open account. After January 1,1992, prices were $\$ 10.25$ and $\$ 10.70$, respectively. These fees cover articles of 10 pages or less; for each additional 10 pages a flat fee of $\$ 2.00$ (deposit) or $\$ 2.50$ (open) is charged (there was a $\$ .10$ increase in 1992). Highvolume customers $(1,200$ or more items purchased per year) may prepay monthly or annually to take advantage of lower costs. "Special service" charges may be incurred for articles which are part of TGA's "Extended Service" (\$7.55 for libraries with a deposit account, $\$ 7.75$ for those with open accounts) and for any copyright fees exceeding $\$ 3.00$.

IOD charges a base fee calculated on two factors: the volume of requests per month and whether the request is filled by IOD-staffed sources or by outside sources. According to the company brochure, this base fee "includes online ordering and online status reports from IOD DIRECT." "Charges for these services are as follows:

$\begin{array}{lll}\begin{array}{ll}\text { Requests/ } \\ \text { Month }\end{array} & \begin{array}{l}\text { IOD- } \\ \text { Staffed } \\ \text { Sources }\end{array} & \begin{array}{l}\text { Outside } \\ \text { Sources }\end{array} \\ 101 \text { or more } & \$ 10.00 & \$ 10.00+\text { costs } \\ 26-100 & \$ 11.50 & \$ 11.50+\text { costs } \\ 1-25 & \$ 13.00 & \$ 13.00+\text { costs }\end{array}$

In addition to the above base charges, each page costs $\$ .35$. Postage fees are passed on, as are any copyright charges. Verification of incorrect citations, if re- quired, reference work required to complete a citation, and charges for phone calls made in order to verify or locate items are also passed on. If it is not possible to photocopy an item, IOD will purchase it directly from the publisher; the cost of the purchase is added to the above charges. There is also a $\$ 4$ handling charge per unfilled order.

Overall, ILL delivered documents on the most timely basis; 65 percent of the time, ILL was the first to send the article.

The base charge for articles ordered from TIF is $\$ 15.25$ for the first 10 pages. For any copies made at California libraries, an additional charge of $\$ .25$ per page for pages over 10 is incurred. Asearch fee of $\$ .25$ is charged for establishing copyright royalty payments, and any copyright royalty fees are charged back. A charge of $\$ 7.50$ is levied for the searching and verification of incorrect or obscure citations or online sourcing. Additional charges may be incurred for purchases from associations or publishers or for special library access; a $\$ 20.00$ limit is in effect unless otherwise specified.

Amounts charged by the various suppliers for the articles requested in this study ranged from no charge to $\$ 49.00$. On 6 occasions, charges were incurred for articles supplied via ILL; the remaining 37 articles were sent free of charge. Of course, all of the commercial suppliers charged for their services. Because we had set up a deposit account with UMI, the charge for each of the 22 articles from this supplier was $\$ 9.75$. Table 4 gives the minimum, maximum, and average charges of the five suppliers.

Costs were compared for articles which were provided by more than 1 supplier. The most expensive was IOD, which charged the most in 31 cases; the least expensive was ILL, which charged the least in 41 cases. Table 5 lists the 10 most expensive articles, and compares those costs with fees charged by other suppliers to fill the same request. 
TABLE 4

CHARGES BY

DOCUMENT SUPPLIER

\begin{tabular}{lrrr}
\hline Supplier & Minimum & Maximum & Average \\
\hline ILL & $\$ 0.00$ & $\$ 5.60$ & $\$ 0.56$ \\
UMI & 9.75 & 9.75 & 9.75 \\
TGA & 9.95 & 21.05 & 14.27 \\
TIF & 12.50 & 32.75 & 18.97 \\
IOD & 13.64 & 49.00 & 20.70 \\
\hline
\end{tabular}

\section{QUALITY OF DOCUMENT}

A document copied in such a manner as to be unreadable by the patron is useless. Accordingly, each document received was rated as to the quality of the copy: poor, fair, good, or excellent. The quality of all 22 articles received from UMI was excellent. For the remaining 4 suppliers, quality was usually excellent or good, with only an occasional fair or poor copy. Poorer-quality copies seemed due to the condition of the original rather than the fault of the document supplier.

\section{SUMMARY AND CONCLUSION}

It appears from the data collected in this study that conventional ILL compares favorably with the services of the commercial suppliers chosen for this study in its ability to provide a cost-effective and reliable means of supplying researchers with the information they need. Furthermore, the average turnaround time for items received via ILL was only one day slower than the average speed of the fastest commercial supplier.

Regarding which supplier was most likely to be able to supply articles requested by our patrons, ILL scored fairly high. UMI and TGA were able to supply less than one-half and one-quarter, respectively, of the materials requested. TIF and IOD had slightly higher success rates than ILL (they were able to supply 89 percent and 87 percent, respectively, of the articles requested, compared to ILL's 83 percent); however, the costs associated with these two suppliers were excessive compared to the slight gain in the number of filled requests.

The commercial document suppliers which had fixed inventory lists and closed, in-house collections (TGA and UMI) were able to supply documents at approximately the same speed as ILL; the average turnaround time for receipt of articles from ILL was 13 days, whereas TGA and UMI filled requests within 12 and 15 days, respectively. TIF and IOD, which have open inventories and rely heavily on staffers who go to libraries to photocopy articles, took longer to fill requests, averaging 22 days for TIF and 23 for IOD. Direct purchases seemed to take an especially long time; of the nine titles listed in table 3 , in 4 instances, the slowest suppliers were those which ultimately purchased the article directly from the publisher.

We were troubled by the fact that for one-quarter of the items requested in this study, IOD found it necessary to charge for additional research in order to fill the requests.

In our study, most of items borrowed via ILL were filled within the local region. Of the 43 requests filled by ILL, 31 were filled by the first library in the string; in 27 instances, the first library in the lender string was located in New York State. The data seem to suggest that it takes both TIF and IOD considerably longer to cycle requests through the various collections available to them. The fact that ILL was able to supply items which were only available from IOD and TIF via direct purchase suggests that the "pool" of information resources available to these suppliers is not as inclusive as it could be. Discussions with a representative from TIF revealed that use of the OCLC database is not an option for TIF. TIF first attempts to fill requests from the 6 or 7 local libraries with which it has agreements; the next step is to search RLIN or sources in Canada. IOD does have access to the OCLC database, but since it considers searching OCLC expensive, this supplier turns first to its sources on the West Coast, and only then searches the OCLC database. 
TABLE 5

COMPARISON OF EXPENSIVE ARTICLES

\begin{tabular}{|c|c|c|c|c|}
\hline Charge & Journal Title & Supplier & $\begin{array}{c}\text { Delivery } \\
\text { Time (Days) }\end{array}$ & Pages \\
\hline$\$ 49.00$ & Journal of the Ancient Chronology Forum & IOD & 85 & 4 \\
\hline 27.75 & & TIF $^{*}$ & 84 & 4 \\
\hline 0.00 & & ILL & 14 & 4 \\
\hline$\$ 33.00$ & Psych. Aspects of Mental Retardation & IOD & 25 & 4 \\
\hline 27.75 & & TIF & 96 & 4 \\
\hline 4.40 & & ILL & 6 & 4 \\
\hline$\$ 32.75$ & Journal of Reproductive \& Infant Psych. & TIF & 23 & 10 \\
\hline 9.75 & & UMI & 8 & 10 \\
\hline 0.00 & & ILL & 10 & 10 \\
\hline unfilled & & IOD & & \\
\hline$\$ 29.25$ & American Journal of Comparative Law & IOD & 9 & 40 \\
\hline 23.00 & & TIF & 14 & 40 \\
\hline 9.75 & & UMI & 9 & 40 \\
\hline 0.00 & & ILL & 10 & 40 \\
\hline$\$ 27.75$ & Sister & TIF & 37 & 1 \\
\hline 21.14 & & IOD & 50 & 1 \\
\hline 0.00 & & ILL & 38 & 1 \\
\hline$\$ 27.75$ & Criminologist & TIF & 18 & 9 \\
\hline 19.25 & & IOD & 18 & 9 \\
\hline unfilled & & ILL & & \\
\hline$\$ 27.75$ & Michigan Quarterly Review & TIF & 42 & 21 \\
\hline 19.58 & & IOD & 11 & 21 \\
\hline 14.95 & & TGA & 8 & 21 \\
\hline 9.75 & & UMI & 9 & 21 \\
\hline 0.00 & & ILL & 8 & 21 \\
\hline$\$ 27.75$ & Le Figaro Litteraire & TIF & 104 & 2 \\
\hline 14.92 & & IOD & 15 & 2 \\
\hline unfilled & & ILL & & \\
\hline$\$ 27.24$ & Journal of Personality Disorders & IOD & 19 & 28 \\
\hline 9.75 & & UMI & 11 & 28 \\
\hline 0.00 & & ILL & 7 & 28 \\
\hline unfilled & & TIF & & \\
\hline$\$ 26.50$ & Cahiers Int'l. de Sociologie & TIF & 28 & 10 \\
\hline 0.00 & & ILL & 6 & 10 \\
\hline unfilled & & IOD & & \\
\hline
\end{tabular}

* filled incorrectly by TIF.

Although the cost of borrowing from commercial suppliers did not involve an obligation to lend, it did include not only certain indirect costs but a direct charge, often substantial. It appears that the suppliers which charge piecemeal for various "extra services" are ultimately the most expensive. ILL, at an average direct cost of $\$ .56$ per article borrowed, was by far the least expensive supplier of the five, followed by UMI, which charged a fixed rate of $\$ 9.75$. The pricing schemes of the other 3 suppliers included additional charges which contributed to increased costs. A perpage charge was levied by IOD in all instances, by TGA for any pages over 10 , and by TIF for any pages over 10 supplied by California libraries. IOD would 
on occasion copy the title page of the journal, and add that page into the total page cost.

Royalty fees were passed on in some manner by TIF and IOD (Note: TGA passes on any royalty charges over $\$ 3$, but this limit was not exceeded in our study). IOD's royalty charges, incurred in nine instances (17 percent), ranged from $\$ 2.50$ to $\$ 7.75$, with an average cost of $\$ 3.70$. In addition to TIF's $\$ 0.25$ charge for establishing royalty payment, charges were incurred 10 times (19 percent) for the copyright royalty itself; this fee ranged from $\$ 2$ to $\$ 10$, with an average of $\$ 3.30$ per item. IOD's postage ranged from $\$ 0.29$ to $\$ 3$, averaging $\$ 0.88$. IOD required "reference work" in order to fill 13 ( 25 percent) of the requests; these charges ranged from $\$ 2$ to $\$ 8$, with an average cost of $\$ 3.15$. In two instances, this fee was charged for articles which IOD was ultimately unable to fill. For 3 items, IOD also charged for phone calls made in connection with filling the request; these charges totalled $\$ 15.50$.

Eight (15 percent) of the articles requested from TIF could not be supplied through conventional channels; TIF supplied them by direct purchase from the publisher or some other source. Costs incurred for direct purchases ranged from $\$ 4$ to $\$ 12.50$, with an average cost of $\$ 10.53$. IOD, which also makes direct purchases, did so on two occasions; one purchase cost $\$ 10$ and the other cost $\$ 20$. It must be remembered that all these fees are in addition to the base costs charged by the suppliers.

We were troubled by the fact that for one-quarter of the items requested in this study, IOD found it necessary to charge for additional research in order to fill the requests. Since most citations were complete, and almost all were cited in a standard source (an index or bibliography), we wondered about staffer background and training, and whether difficulty in interpreting bibliographic citations added to the delay.

Differences among the 5 suppliers in terms of quality were negligible. Only 2 copies were judged to be so poor as to be difficult to read; the other copies were all passable. Once again, with the exception of the documents supplied by UMI, which were consistently of superior quality, higher costs did not guarantee better service.

Given the above findings, in most cases the use of commercial document delivery suppliers did not appear to be a more effective or efficient means of obtaining access to articles not available at our library. There may be occasions, however, which warrant the use of commercial suppliers. When items are needed urgently, special ordering from commercial document suppliers with fixed inventories, while expensive, may be worthwhile since receipt of the article is guaranteed (except when copyright or other limitations are reached). Additionally, the high quality of UMI's copies and/or TGA's tear sheets may be desirable when high resolution is needed for photographs or other graphics. Because TIF and IOD failed to provide materials in a timely manner, and because additional charges are likely to be incurred when filling requests, it would seem unwise to choose these vendors over ILL, except in cases where all other options have been exhausted.

\section{REFERENCES AND NOTES}

1. Jean Currie, "Document Delivery: A Study of Different Sources" (Report dated 1985 to the Council on Library Resources). Available from the author at the South Central Research Library Council, 215 North Cayuga St., Ithaca, NY 14850.

2. Douglas P. Hurd and Robert E. Molyneux, "An Evaluation of Delivery Times and Costs of a Non-library Document Delivery Service," in Energies for Transition: Proceedings of the Fourth National Conference of the Association of College and Research Libraries, ed. Danuta Nitecki (Chicago: ALA, 1986), 182-85.

3. Connie Miller and Patricia Tegler, "An Analysis of Interlibrary Loan and Commercial Document Supply Performance," Library Quarterly 58 (Oct. 1988): 352-66.

4. UMI Article Clearinghouse Catalog, 1991, 10. 
5. Information Store: Professional Document Retrieval Services, n.d., n.p.

6. Vernon E. Palmour, comp., A Study of the Characteristics, Costs, and Magnitude of Interlibrary Loans in Academic Libraries (Westport, Conn.: Greenwood, 1972), 22.

7. Stephen P. Dickson and Virginina Boucher, "A Methodology for Determining Costs of Interlibrary Lending," in Research Access through New Technology, ed. Mary E. Jackson (New York: AMS Pr., 1989), 137-59.

8. Mary E. Jackson, "Fitting the Bill," Wilson Library Bulletin (June 1992): 95-97.

9. Edward Meachen, "Traditional Interlibrary Loan and Document Delivery Systems: The Relative Costs" (Paper delivered at the Meckler Document Delivery \& Libraries/Internet \& Libraries Conference, Philadelphia, Dec. 7/8, 1992).

10. Marilyn M. Roche, ARL/RLG Interlibrary Loan Cost Study (Washington D.C.: Association of Research Libraries, 1993).

11. IOD Price Schedule (McLean, Va.: Information on Demand, 1991).

\section{IN FORTHCOMING ISSUES OF COLLEGE \& RESEARCH LIBRARIES}

Librarians, Self-Censorship, and Information Technologies John Buschman

Improving Reference Service: Borrowing Ideas on "Quality" from the Business Literature Janet Dagenais Brown

Scholarship and the Academic Librarian

William K. Black and Joan M. Leysen

A Conceptual Analysis and Overview of Information Literacy

Shirley J. Behrens

Scientists' Access and Retrieval of References Cited in Their Recent Journal Articles Julie Hallmark 


\section{Real customer service.}
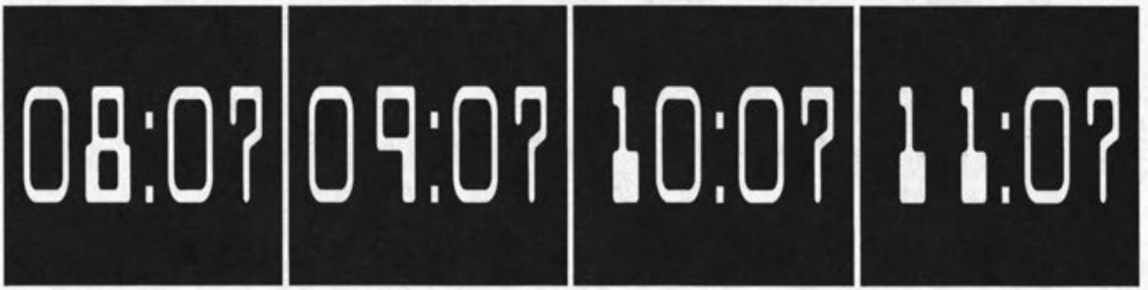

\section{In real time.}

Providing the level of personal service we believe in requires being available when our customers need us. So our 11 regional offices in North America are staffed with customer service representatives who are only a phone call away. With at least one regional office located in each of the four major time zones, it's more likely our representatives will be where you need them when you need them - not several hours away.

We believe in providing real customer service in real time.

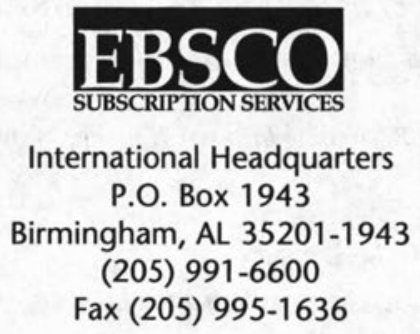

North American offices located in Birmingham, Ala.; Chicago; Dallas; Denver;

Los Angeles; Montreal; Red Bank, NJ; San Francisco; Tenafly, NJ; Toronto; and Washington. Seventeen offices located throughout the rest of the world. 